\title{
Informing Learning Design with Learning Analytics to improve Teacher Inquiry
}

\section{Please quote as follows:}

Persico, D., \& Pozzi, F. (2015). Informing learning design with learning analytics to improve teacher inquiry. British Journal of Educational Technology, 46(2), 230-248. doi: 10.1111/bjet.12207

\begin{abstract}
This paper proposes an analysis of current research in learning design (LD), a field aiming to improve the quality of educational interventions by supporting their design and fostering the sharing and re-use of innovative practices among educators. This research area, at the moment, focuses on three main strands: the representations that can be used as a common language to communicate about designs, the methodological approaches to learning design and the tools that support the design process. For each of the three strands, the current landscape is discussed, pointing at open issues and indicating future research perspectives, with particular attention to the contribution that learning analytics can make to transform learning design from a craft, based on experience, intuition and tacit knowledge, into a mature research area, grounded on data concerning the learning process and hence supporting enquiry while teachers design, run and evaluate the learning process.
\end{abstract}

\section{Keywords}

Learning Design (LD), learning design representations, learning design approaches, learning design tools, Learning Analytics (LA), teacher enquiry.

\section{Introduction}

Todays' educators are facing many challenges. The objectives of education are changing, from the acquisition of a relatively stable set of competences to the need of empowering learners with the ability to learn and work in autonomy or with others in a fast changing world, where knowledge is dynamic and technology is pervasive. Learners are also changing, they live in a technology rich environment, they learn very fast how to handle new tools and media but often underestimate their power, both in the positive and negative sense, because they do not always appreciate and take advantage of their affordances neither do they always perceive the risks inherent in their use, as the frequency of cyber-bullying (Smith, Mahdavi, Carvalho, Fisher, Russell, \& Tippett, 2008) and other unethical online behaviours seem to demonstrate. Besides, teacher-centric pedagogical approaches do not seem to meet learners' needs. As a consequence, teachers are expected to be able to orchestrate technology rich environments and facilitate learning processes where students are challenged by authentic learning tasks and are encouraged to self-regulate themselves, as needed by aware and responsible citizens of the digital society.

In this context, teachers need to make effective use of technology. While there still are resistances to the use of technology in teaching, many teachers today try to make effective use of technology in education in the belief that this will improve their teaching, their relationship with their students, and their ability to engage them in effective educational experiences. To achieve this goal, their mode of working must become heavily reflective, explorative, and experimental, like that of educational researchers (Laurillard, 2008). In other words, their work is bound to resemble more and more to scientific enquiry, because their reflective practice needs to be based on innovative experience, not only their own, and to be informed by data. However, 
and in spite of the fact that new technologies have been proved to have potential for learning, best practice examples of technology use in the classroom are not so frequent and the teachers who make systematic and pedagogically informed use of technology are still a small bunch of early adopters (Rogers, 1995), rather than an early majority of professional users. Some researchers in Technology Enhanced Learning (TEL) (Mor \& Craft, 2012; Persico \& Pozzi, 2013) claim that there is a gap between the promises of TEL research and the practice in educational institutions. They maintain that only the spreading of a participatory culture of learning design (LD) can support better and more widespread use of technology in education, and that $L D$ research should be headed towards this objective. Several national and international projects (LDG Theme Team ${ }^{1}$, METIS Project ${ }^{2}$, JISC project $^{3}$ ) as well as publications testify to these efforts and seem to confirm that facilitating the sharing of good practice and good designs is one of the main aims of this area of work (Britain, 2004; Conole, 2013; Goodyear \& Retalis, 2010; Laurillard, 2012; Lockyer, Bennett, Agostinho, \& Harper, 2009; The Larnaca Declaration on Learning Design, 2012). However, the very concepts of good practice and good designs need to be better defined. Although teachers judgement about the suitability of an approach or method to a given learning context is important, when the innovation leads out of the "plowed field" of experience, evidence based research is needed to discern between alternative educational approaches. The wealth of data made available in real time by Learning Management Systems and e-learning platforms, if suitably processed through learning analytics (LA) methods and tools, offers students, teachers, lecturers and designers timely and reliable information that may support their decision-making processes at different stages of the educational system development cycle.

The following section introduces the LD concept, while the subsequent section discusses how and when LA can improve the educational system development cycle, thus setting the scene for the main focus of the paper, that is, a discussion of the three main research threads dominating LD research (research on representations, approaches and tools) and of the contribution that LA can give to each of them, and to Teacher-led Inquiry (TI), pointing at open issues as well as a possible way ahead.

\section{A view on the learning design research field}

The field of LD has gained attention among researchers and practitioners during the last decade, although it is deeply rooted in a much older research area: Instructional Design (ID). ID dates back to World War II (Reiser, 2001), when the US invested significantly to make the design of educational programs and courses more systematic, for more effective and efficient education and training processes, especially for critical skills and large target populations. The ID field evolved hand in hand with learning theories and technology developments. The aim was to develop methods and tools for making the process of designing and delivering instruction as systematic, efficient and effective as possible. According to most ID models (Persico, 1997), the development of an instructional system starts from the analysis of the learning needs and the learning context requirements, moves through the definition of the specifications and the identification of suitable approaches and tools, down to the development or identification of the needed educational resources and assessment tools. The delivery consists of the actual implementation of the instructional process and entails the collection of data for its ongoing evaluation and fine tuning.

\footnotetext{
${ }^{1}$ The 'Learning Design Grid (LDG)' Theme Team (http://www.ld-grid.org/) was funded by the STELLAR Network of Excellence (7FP) from 2011 to 2012 and this RLT issue is one of its results.

${ }^{2}$ http://metis-project.org/

${ }^{3}$ http://www.jisc.ac.uk/
} 
Several authors (Gustafson \& Branch, 2002; Van Rooij, 2010) refer to this approach as the ADDIE model (acronym for Analysis, Design, Development, Implementation and Evaluation) and describe it as a sequential and iterative process to systematically develop instructional systems. Interestingly enough, a careful investigation of the origins of this term revealed that there does not appear to be an original, authoritative version of the ADDIE model in the literature (Molenda, 2003), rather, ADDIE is an umbrella term identifying a family of models that share the above described, common underlying structure. It is also generally recognised that evaluation should take place as early as possible for the costs of amending the design to be minimized. ID methodologies therefore include approaches for the definition and use of quality control measures aimed at collecting data to perform the formative evaluation of the instructional process being developed. These data are collected before, during and after delivery.

While the results obtained by ID research have turned out to be very useful to optimize the development of large instructional programs, they are more difficult to apply to small scale, everyday education, so that the design of educational interventions, for individual teachers and designers, is still a craft, effectively compared by Conole (2013) to the performance of a juggler who needs to strike a balance between the educational aims, the features of the target population, the affordances of available technology and the constraints of the learning context. More recently, a new expression has come into use, i.e. learning design (LD); this expression, which stresses the notion of learners' centrality, has almost replaced Instructional Design, at least in Europe. The origins of the term can be traced back to the work of two OUNL researchers (Koper \& Manderveld, 2004) who developed the IMS-LD specification and, subsequently, an Educational Modelling Language aimed at enabling the expression of units of learning embodying many different pedagogies. Today, however, this is used in a much broader sense, mainly in Europe and Australia, by researchers who concentrated more on the importance of facilitating practitioners in the sharing, modification and reuse of their pedagogical plans ${ }^{4}$. Some researchers (Smith \& Ragan, 2005) have noted that the expression "learning design" is almost misleading, and that "design for learning" would be much more appropriate, since LD seems to suggest that learning can be designed, while only environments or tools to support learning can be designed. While we agree with this point, in this paper, we will use the most common LD acronym for the sake of brevity. The main difference between the LD and ID fields (Conole, 2010a; Dobozy, 2011; Mor \& Craft, 2012) is not just a terminological one, neither is it only related to the learning theories embraced. The main difference, in the authors' opinion, is about where the focus of attention is cast: while ID mostly focuses on methodological support to make the design process more systematic, LD researchers mostly work towards the objective of making already produced designs easier to share and reuse. In particular, the rationale of the line of work on LD is based on what are perceived to be the needs of today's individual educators, rather than those of educational technologists engaged in the systematic design of big instructional programs.

Indeed, the fast development of technological tools and the evolution of their affordances is making very difficult for individual educators to be always updated on the potential of technology and its strategic use in education. In addition, even students' needs are changing, because their learning habits and strategies change due to pervasiveness of digital tools in our society. To keep the pace of these developments, today's educators, more than ever before, need to break their traditional isolation and build upon each other's shoulders to develop more solid, extensive and dynamic design competence based on collective practice (Conole, 2013).

\footnotetext{
${ }^{4}$ The term "pedagogical plan" is used here to identify the product of the LD activity, in order to avoid the frequent ambiguity between LD to mean the activity of designing and LD to identify the output of the same activity,
} 
Research in LD thus looks at the design process as a collaborative inquiry endeavour by teachers (Mor \& Mogilevsky, 2013) and assumes that the creation of communities of educators and designers sharing experience and practice is a necessary, although not sufficient, condition for allowing educators to learn how to make better informed choices when facing design problems (Laurillard, 2012; Walmsley, 2012). To facilitate the development of these communities of practice, LD researchers have been trying to provide them with powerful conceptual and technological tools to support the sharing, reuse, and reflection needed to make the design process more systematic, pedagogically informed and, eventually, effective (Earp, Ott \& Pozzi, 2013). Among the conceptual tools, two areas of work have been particularly fertile: the first consists of a number of studies concerning the way pedagogical plans and learning designs can be represented, and the second includes the development of approaches to support the sharing, reuse and enactment of designs. As for the technological tools, these are often associated with one or more representations and approaches. In this paper, we concentrate on these three research strands (representations, approaches and tools) to provide a picture of the current landscape, and discuss the contribution that LA can make to transform LD from a craft into a more sound and evidence-based field of research. To this end, before focussing on the three strands, the next section provides a view on the contribution that LA can make to the LD field.

\section{The relationship between Learning Analytics and Learning Design}

LA, intended as "the measurement, collection, analysis and reporting of data about learners and their contexts, for the purposes of understanding and optimizing learning and the environment in which it occurs" (call for papers of the first International Conference on Learning Analytics and Knowledge, 2011, cited in Ferguson, 2012: p.2), can be said to have effectively contributed to the ID field from its early days, even before the terms LA and LD were coined. In fact, the evaluation phase of the ID process entails the collection of qualitative and quantitative data to inform the revision and fine tuning of the instructional system under development.

However, the LA field of research today aims to make use of the results of recent, though preexisting areas of work, such as business intelligence, Educational Data Mining, web analytics and recommender systems, to investigate the way big data handling techniques can be used to analyse large, machine readable sets of educational data and distil summaries or synopses based on suitable numerical or graphical data representations to support decision-making of the different actors involved at different stages in the learning process.

Figure 1 presents this view through a graph where activities are represented as rectangular boxes, input nodes are the resources needed to perform the activities (humans or data) and the output nodes are the products of the activity. The different actors, in this figuree, represent different roles that in practice can be covered by the same person (the designer can also be the tutor and/or the analyst). According to this view, the process of LD can be informed not only by the experience of the designer and by the best practice of their colleagues, but also by preexisting aggregated data on students engagement, progression and achievement (such as the rate of success of different approaches in different contexts, statistics about student preferences or problematic areas, etc). The pedagogical plan produced on these bases is better informed and has more chances to be successful. Subsequently, the enactment of the pedagogical plan will see the involvement of two kinds of actors: tutors, who might use LA tools to make just-in-time pedagogical decisions (i.e. contacting students whose participation is low or forming groups of students based their performances) and students, who can base their own self-regulation and personalise their learning environment on LA produced information (e.g. average time needed to study a module, personal and average assessment results and other data tracked by the system). For the sake of clarity, in Figure1 the different LA functions are represented as three separate boxes, distinguished from the LD activities, and LD is split into two main phases: 
pedagogical planning and enactment. However, the distinction between LA for designers, tutors or students is merely functional, rather than logical or physical, since LA research very sensibly sees LA methods and tools as a whole. Similarly, LA modules should be integrated into LD methods and tools so that users, be them designers, tutors or students, will have aggregated data at hand while planning, tutoring or learning.

To take advantage of LA potential, research on LD should therefore harness the results of the research this field of research (Lockyer \& Dawson, 2011) and integrate its methods and tools with those of LA. This would help positioning teachers as learning designers capable to carry out design-based research (Mor \& Mogilevsky, 2013), and encourage students ito self-regulate their learning process based on personal and others' learning experiences.

\section{Figure 1: How LA can improve the learning process by informing decision-making of different actors involved.}

\section{Learning design representations}

As already mentioned, one of the main directions undertaken by research in LD has focused on the attempt to develop representations of the products of the LD process (Agostinho, 2009; Conole, 2010b). The assumption is that making the product of the LD process more explicit, easy to understand and better formalised is essential to provide maieutic support to the design process, facilitate sharing and reuse of pedagogical plans and automate some of the design phases. The quest for a representation formalism in LD is aimed at obtaining a common, unambiguous lingua-franca allowing teachers to understand each other's design, to reuse and interpret with little effort good pedagogical practice originated by someone else.

Important qualities of these formalisms are (Olimpo, 1995): expressiveness, that is, ability to effectively communicate ideas, ease-of-use by non-specialists, abstraction power (to dominate complexity and representing unrefined ideas), ability to represent different points of view, flexible paths, alternative ideas and optional routes. Most of the representations proposed for LD are graphical representations or languages that allow to describe pedagogical plans of an activity or a course or some relevant feature thereof (Pozzi, Persico \& Earp, 2014).

LD representations can vary in format and type. Broadly speaking, formats fall into two main categories: textual representations (languages) and visual representations. According to Conole (2013), textual representations are expressed in either artificial/formal or natural language (narratives), while visual representations are basically in a graphical format. Textual and visual representations are often used in conjunction with one another. In fact, one format alone is often insufficient to convey all the needed information (Falconer, Beetham, Oliver, Lockyer \& Littlejohn, 2007).

Textual representations through artificial languages describe the design in a highly formalized way, usually so that it can be processed by a computer. This makes it possible to deliver relevant components of a learning activity directly to learners or provide for automatic configuration of a suitable computer-based learning environment in which the activity can take place. Describing a design through such formal languages is usually a fairly technical matter. Consequently it may call for involvement of a professional with the necessary technical competences to act as a 'bridge' between teacher and computer, or for a high-level interface that 'masks' the technicalities and allows the teacher to focus on design considerations.

Textual representations based on natural language, instead, are largely 'narratives', i.e. descriptions of designs, plans or experiences based on words (for an example, see a narrative description of a Problem Based approach in Fig.2a). As such they typically have a low degree of formalism. However, they are often based on a pre-defined skeletal structure, such as an organized schema of descriptors or fields, for expressing various aspects of the design (an 
example is the Course map template ${ }^{5}$ ). This provides the teacher with guidance about the way the design is conceived and developed, the choices to be made, the information that the description is to contain, and the level of detail required. In some narrative forms, basic and abstract information about the design is given greater emphasis than contextual details, which may even be excluded altogether. This facilitates instantiation of the design artifact in a specific context and thus increases the potential for reuse, replicability and scalability. An example is provided by Design Patterns, that have been used as means to share both learning designs (an example are the Learning Design Patterns, described in McAndrew, Goodyear, Dalziel, 2006), as well as recurrent practices in the field of data collection and analysis (Persico, Pozzi \& Sarti, 2009), as it happened in the DPULS project (Design Patterns for recording and analysing usage of learning systems ${ }^{6}$ ). Hence, Design Patterns have been proved to effectively serve the double purpose of sharing learning designs, as well as practices of LA.

\section{Figure 2: (a) Narrative representation of a Problem Based learning approach (b) itsUML diagram (b). Excerpt from IMS Global Learning Consortium (2003).}

Other kinds of narratives are intended to include more detailed information, which may be related to the pedagogical rationale behind the intervention and/or the details of the "enactment" phase. For example, Mor (2011) proposes the use of an account of critical events in a design experiment from a personal, phenomenological perspective. This approach sees design as a problem solving activity and aims at documenting it through account of its history and evolution over time, including failed attempts and the modifications they espoused. The latter may be considered to "flesh out" the design skeleton with tangible descriptions of the way the learning activity has been or can be used, the context that the activity is intended for, the target population to be addressed, its prerequisites, etc. This idea could be extended to include a discussion of the data available concerning the learning process, that could be shared as data sets as researchers already do in many fields of science.

Visual representations, on the other hand, generally take the form of diagrams or graphs, conveying an overall view of the design or specific aspects thereof, such as the structure of the intervention, the learning objectives, the contents to be addressed, the roles of the people involved, etc. Diagrams or graphs are a means to represent the main entities within a design and their mutual relationships; they include flow charts, content maps and swim lanes (Dalziel, 2003; Paquette, Léonard \& Lundgren-Cayrol, 2008; Conole, 2011). One of the most well known is the UML Activity Diagram, exemplified in fig. $2 b$.

Content maps, in particular, are often used also in the evaluation phase, i.e. to represent the structure of the domain, where the nodes represent topics or aspects that one should monitor/check/assess during and at the end of a learning path. This kind of representation can be effectively used both to improve the LD process, and to define the learning indicators and analytics that need to be considered. LA techniques can provide data about the individual or collective learning experience, including, but not limited to, assessment results, mapped to the relevant content domain representation. For example, content maps in the form of graphs can be enriched with data about student performance or preferred activities associated to each node to provide a picture of the strengths and weaknesses of the learning process while it still takes place. These information are useful to the tutors, to support them in their decisions, to the designers, to amend and improve their materials and designs, and to individual students, as a basis to self-regulate their own learning. Another example of use of this kind of representations in the field of LA is suggested by Lockyer, Heathcote and Dawson (2013), who propose Social

\footnotetext{
${ }^{5}$ http://jiscdesignstudio.pbworks.com/w/page/33031185/OULDI\%20-\%20Course\%20Map

6 The DPULS was a JEIRP funded under the Kaleidoscope Network of Excellence (http://eiah.univlemans.fr/demos/dpuls/login.faces).
} 
Network Analysis diagrams representing students' interactions during an activity, to inform on the run teacher's interventions.

Charts, on the other hand, are visual representations of quantitative data from the intervention; bar or pie charts representing features of the learning process, based on suitable indicators, are typical examples. These charts usually foster reflection on the design by focusing attention on the specific aspects represented. One example of these are pie charts showing the balance between different kinds of approach within the design of a whole course (San Diego, Laurillard, Boyle, Bradley, \& Ljubojevicb, 2008). Charts can also be built as a result of data collection and analysis during the delivery of a learning activity, to represent aspects of the learning process as this is being enacted by the students, in such a way to inform the subsequent tutors' actions. As an example, Dias and Diniz (2013) propose to use a Fuzzy Quality of Interaction model to create on the fly charts representing students' and teacher's interactions, to be shown to teachers so that they can tune and adapt their initial designs.

From the above considerations emerges that, while different representation types have different advantages and drawbacks, we are still rather far from the identification of the lingua franca for LD. Some representations are more suited to support communication among individuals; others to automate the instantiation of a learning environment. Some were developed for specific types of pedagogical approaches, while others are claimed to be "pedagogy independent". In most cases, however, the representation alone does not facilitate the decision-making process of the designer, it simply provides a way to express the result of such process. When enriched with information concerning previous or ongoing learning processes, instead, it may indicate the quality of the design, or the preferences of certain learners with respect to delivery mode, so that adaptability to a given context and target population can be deduced. However, if the representation is meant to be interpreted by a computer and implemented into a learning environment, then all the details needed for implementation must be provided and this often jeopardizes user-friendliness and communicative power.

It is interesting to note that although the LA research field is evolving in parallel to the LD field, the problem of finding suitable and easy to interpret representations for the outputs of the two activities is similar. LA, so far, has focused on visual representations, consisting of graphs and charts, or tables of data. One promising way ahead is to combine together LD and LA representations, as indicated in the above example of content domain representation enriched with students performance indicators. The possibility for the designer to access representations of what happened in past learning experiences and for the tutor and the student to see what is happening during the delivery of a learning activity allows real-time tuning of their actions. While the LA literature has so far concentrated on the use of LA tools to support the tutor and the student (Bakharia \& Dawson, 2011; Blikstein, 2011), less has been made to inform the design phase, and this would be a promising way ahead for the LD field.

\section{Learning design approaches}

A second LD research strand concerns the development of approaches aimed at guiding the decision-making process. This strand of research shares some basic concepts and ideas with the ID research sector, even if LD usually looks at the design of a single (or a sequence of) activity(/ies), while ID is typically focused on the course/programme level. Generally, LD approaches are intended to help both novice teachers, who may not be familiar with the decision criteria that are at the heart of the design process, and experienced teachers who intend to design activities with some innovative features, such as the use of a new technological tool. An overview of existing approaches to LD is provided in (Persico et al., 2013).

Some of the approaches developed within the LD research area are focused on one pedagogical theory and thus lend themselves better to support the design of specific kinds of activity, while others are general purpose, that is, they are not related to any specific type of pedagogy and 
have the ambition of suiting a broad range of learning contexts. The same happens with LA methods: some of them, such as Social Network Analysis, lend themselves very well to analyse socio-constructivists learning processes (Aviv, Erlich, Ravid, \& Geva, 2003; De Laat, Lally, Lipponen, \& Simons, 2007), while others are more general purpose.

Among the first category of LD approaches, an example is the 4SPPIces approach (PérezSanagustín, Santos, Hernández-Leo, \& Blat, 2012), a conversational framework to support dialogue between teachers and technicians, specifically aimed to facilitate the design of Computer-Supported Collaborative Blended Learning activities. 4SPPIces identifies four factors: the Space (S), the Pedagogical method (PM), the Participants (P) and the History $(\mathrm{H})$. Each of the factors is composed by a set of facets that are explained in detail as part of the same design. A set of questions epitomizes the aspects included in the facets, aiding the recognition of relevant issues that could affect the decision-making process.

Another example of this category is the 4Ts approach (Pozzi \& Persico, 2013), developed to support decision-making and pedagogical planning for Computer Supported Collaborative Learning (CSCL) activities. As its name indicates, it looks at four main aspects the teacher needs to focus on in their decision-making process: Task, Teams, Technology and Time. The rationale for the 4Ts is that, while designing an online collaborative learning activity, teachers need to define the nature of the Task students will be asked to carry out, choose the Teams' composition and interaction modes, identify the phases of the activity by providing the overall Time schedule and select the Technology, i.e. the medium through which interactions will occur. In the 4Ts model, the teacher/designer juggles with these 4 variables, with no predetermined or mandatory order: each decision concerning any of the four dimensions is influenced by the others and the other way around.

Among the general purpose approaches is ISiS (Emin, Pernin, \& Guéraud, 2009). This approach aims to capture the teachers' intentions and strategies to facilitate understanding of learning designs by others, and to favour sharing and reuse. It describes three dimensions of a design: intentional (designers' intentions, linked to targeted knowledge items such as competences or abilities); strategic (related to the teaching methods and strategies); and tactical (related to the interactional situation, the solution to implement the formulated strategies and intentions).

Similarly, the 7Cs approach, developed and tested at Leicester University and at the Open University in UK, proposes and integrates a set of resources for technology-enhanced learning design across disciplines based on seven key actions: Conceptualize, Capture, Create, Communicate, Collaborate, Consider, and Consolidate.

Still in this category, the design-inquiry approach (Mor \& Mogilevsky, 2013) proposes to apply the pedagogy of inquiry-based learning to the scientific paradigm of design-based research, thus giving birth to the cycle of "design-inquiry learning", which encompasses: imagining a desired change, investigating the current situation, drawing inspiration from theoretical frameworks and exemplars of practice, ideating and designing an innovation, prototyping it, evaluating its effects and reflecting on the process.

While the approaches briefly described so far consist of methods to go about in the decisionmaking process, others rely on a distillation of pedagogical principles for designers to apply. For example, the e-Design Template is a pedagogical approach developed on constructivist principles from a range of other guides and models. It is intended to support practitioners when creating constructivist-inspired e-learning activities and when reviewing and sharing learning designs (Walmsley, 2011).

In general, the critical decisions made by the designers are based on their knowledge about the teaching and learning context, their teaching experience and their competence about the technology affordances. In many cases, however, they lack some relevant information that would effectively support the decisions. For example, in the 4Ts approach, the designer should take decisions about the team's composition, or the time needed to their students to carry out a 
given task. LA could provide data about previous learning dynamics of the same students or also other students in similar contexts, including information on task performance, learning outcomes, problems arisen and solutions adopted. In other words, the effectiveness of the approaches previously described could be greatly increased if the knowledge base shared by the designers included not only reusable designs, also data about their previous application. This would allow teachers to anticipate problems, choose effective solutions, and manage the activity with more hindsight. LA based information about previous learning behavior of the same students would also allow to build well balanced teams, estimate time devoted to task by course participants, choose suitable technological environments, draw analogies with similar activities and carry out comparative evaluations.

The existence of so many different approaches suggests that many researchers have felt the need to systematize the methods they used in design, and produce some kind of guidelines on how to proceed in this task. However, although many of these approaches share some common features, there has not been an attempt to build a unified vision. This research area somewhat suffers from the specificities of the contexts where they originated. More importantly, the lack of convergence and the proliferation of new approaches inevitably nurtures the fragmentation of the field. The killer argument that would be likely to force practitioners, if not researchers, to choose one approach, would be the availability of an effective and easy-to-use tool, incorporating one of the approaches. Indeed, some of these approaches have inspired the development of tools to support the design, but even in this case, none of them have yet proved capable to become a standard and thus make its underlying approach more widespread than the others. What is worse, the number of tools that have been developed is perhaps even higher than that of the approaches, as we will see in the next section.

\section{Learning design tools}

An amazing number of tools exists to assist teachers in planning learning outcomes, activities, assessment and other aspects of LD. According to Prieto et al. (2013), LD tools generally have a common goal of enabling the sharing, adaptation and reuse of practitioners' pedagogical ideas, and are useful also to facilitate reflection (Laurillard, 2012).

However, as noted by Conole (2010b), each LD tool employs some kind of representation, explicitly or implicitly support the adoption of a design approach and pedagogical theory, focuses on and operates at different levels of granularity - from simply capturing the essence of a design, to describing all the details needed to aid the implementation of its enactment.

In this paper, we distinguish among reflection tools \& pedagogical planners, authoring \& sharing tools, repositories, and delivery tools.

Among the reflection tools \& pedagogical planners we consider those tools that are oriented to help the teacher/designer reflect on the pedagogical choices to take, thus supporting the process of decision-making. Some tools in this category are the direct expression /reification of a LD approach (see above section); so for example the LdShake tool (Hernández-Leo et al., 2011) reifies the 4SPPIces approach, while the ScenEdit tool (Emin, Pernin, \& Aguirre, 2010) stems from the ISiS approach.

Another example in this category is the Pedagogical Plan Manager (Olimpo, Bottino, Earp, Ott, Pozzi, \& Tavella, 2010), which was created with an explicit maieutic function, to help the teachers express the pedagogical rationale behind their choices. In this category also falls Pheobe $^{7}$, a web application designed to provide inspiration and practical support for LD, developed by the university of Oxford.

\footnotetext{
${ }^{7}$ http://www.phoebe.ox.ac.uk/
} 
Another tool, the Learning Designer ${ }^{8}$, represents learning designs using formal learning concepts (e.g. Bloom's taxonomy of learning outcomes, types of learning), underpinned by semantic technologies. This tool provides visual analytics of the learning designs (for example, in the form of pie charts representing the character of the designed learning experience) and intelligent recommendations using community knowledge (Laurillard et al., 2011). These computer-interpretable representations allow the teacher/designer to assess and reflect on the choices made, in order to tune the design. Among the tools mentioned so far, this is the one which is closer to the logic of LA: the data accessed are limited to the pedagogical plan under development, but the idea of representing its features based on likely effects is one that might take advantage of aggregated data produced through LA functions.

Among the authoring \& sharing tools, some allow the representation of activities and are rooted in specific pedagogical models: it is the case of Web Collage, a graphical tool aimed at representing collaborative learning activities (Villasclaras-Fernández et al., 2011). Web Collage integrates a set of Collaborative Learning Flow Patterns (or CLFPs, see HernándezLeo et al., 2006), describing well known collaborative techniques such as the Jigsaw, or the Pyramid. The teacher can choose a technique and instantiate it, by providing contextual details, such as the learning objectives, the resources to be used, the assessment activities to be carried out, etc.

Other tools allow different representations/visualizations of the same activity or flow of activities. For example CompendiumLD ${ }^{9}$ supports the creation of several visual representations of a learning design, while CADMOS (Katsamani \& Retalis, 2011) allows the production of two different models: a conceptual model (describing the learning activities that the different roles of the design are involved in, and the corresponding learning resources/services) and a flow model (describing the orchestration of the learning activities). Similarly, the LDTool, developed at the university of Wollongong, represents learning designs using the LDVS format (Agostinho, 2011).

The repositories are intended to provide practitioners with success stories, design ideas, reports of experiences, best practices, etc. This is the case for SD2 (Earp, Ott \& Pozzi, 2013), and Cloudworks ${ }^{10}$, "a place to share, find and discuss learning and teaching ideas and experiences", as stated in the Cloudworks website. Another example in this category is the Design Principles Database $^{11}$ (DPD), which was developed to capture, coalesce and synthesize design knowledge (Kali, 2008). Other examples include the Pedagogical Pattern Collector ${ }^{12}$, enabling teachers to share their teaching ideas (as well as allowing them to instantiate already existing patterns); the Learning Designs ${ }^{13}$ database, which includes a set of proven learning designs; and The Design Studio - JISC ${ }^{14}$. The list of the existing repositories cannot be exhaustive, as there are really many sources of this kind on the web; the above mentioned repositories exemplify the variety and richness of this research thread. A natural evolution of these tools in the LA direction would be that of enriching the database with LA produced aggregated data providing evidence for the criteria and principles stored in the database.

As anticipated, other tools are oriented to the delivery of learning activities to students: it is the case of LAMS ${ }^{15}$, and of many IMS-LD based tools, such as for example CeLS (Ronen, KohenVacs, \& Raz-Fogel, 2006) and OpenGLM (Derntl, Neumann, \& Oberhuemer, 2011).

\footnotetext{
${ }^{8}$ https://sites.google.com/a/lkl.ac.uk/ldse/

${ }^{9}$ http://compendiumld.open.ac.uk/

${ }^{10} \mathrm{http}: / /$ cloudworks.ac.uk/

${ }^{11} \mathrm{http}: / /$ edu-design-principles.org

${ }^{12}$ http://web.Ikldev.ioe.ac.uk/PPC/live/ODC.html

${ }^{13} \mathrm{http}$ ://www.learningdesigns.uow.edu.au/

${ }^{14} \mathrm{http}: / /$ jiscdesignstudio.pbworks.com/w/page/12458381/case\%20studies

15 http://www.lamsfoundation.org/index.htm
} 
It should be noted that some of the tools originally intended as authoring and sharing tools, have been afterwards extended to allow enactment and delivery. It is the case of the above mentioned Web Collage, which, working alongside with GLUE!-PS (Prieto, Asensio-Pérez, Dimitriadis, Gómez-Sánchez, \& Muñoz-Cristóbal, 2011), can now deploy the learning designs into an LMS, creating automatically the needed activities, groups, resources, etc.

Interestingly, some of the most cutting-edge delivery tools also embed tracking and monitoring functionalities, thus supporting data collection and LA during the enactment phase: it is the case of GLUE!-PS, the tool developed at the University of Valladolid to enact WebCollage's pedagogican plans. Since most of the research in LA has focused, so far, on methods and tools addressing the needs of tutors and students at enactment time rather than designers at planning time, it follows that harnessing LA research results to enhance this type of tools should be easier than it is for pedagogical planning tools. A first step in this direction has been made by FORMID (Lejeune \& Gueraud, 2012), an authoring tool that delivers activities to students and, simultaneously, builds a web-based interface for tutors' observation needs.

This long (and not exhaustive) list of tools demonstrates that there have been groups of researchers working in parallel, with relatively low coordination and a high risk of fragmentation of the field. In addition, some of these tools have had a rather short lifespan, due to a general difficulty to raise funds for the sustainability of their development and maintenance. The METIS project ${ }^{16}$, recently launched under the LLP EC programme, acknowledges this situation and is presently building a platform, called Integrated Learning Design Environment (ILDE), embedding a number of the above mentioned tools and offering guidance in the tool selection, based on the designers needs. Very few tools, however, go as far as to enhance the delivery environment with LA functionalities while none, to our knowledge, make use of LA to support the teachers/designers in their inquiry process in the design phase.

\section{Discussion}

The previous sections show that the LD research area is very lively, and the three main strands of work can all take advantage of LA results, in different ways. Also, the way ahead in some areas is clearer and to some extent already explored, while in others is more blurred and yet to be identified.

\section{Representations}

A great effort has been devoted so far to the definition of formalisms and representations, to make the output of the LD process explicit and sharable and to facilitate communication and reuse of complex and powerful pedagogical ideas. The types of representations that are being used in LD have been classified and their features analysed, in terms of strengths and weaknesses (Conole, 2010b; Agostinho, 2009; Falconer, Beetham, Oliver, Lockyer, \& Littlejohn, 2007). A feature missing from many of the representation formalisms proposed so far is the possibility to represent flexible designs, where the student can choose among different paths. This is an important feature if the possibility of personalizing one's own learning path, and therefore self-regulating ones' own learning, is envisaged. Such a possibility would lead to a natural integration with results from the field of LA, by associating to each possible path the percentage of students that have chosen that option rather than the other(s), thus providing information about their preferred approaches.

More generally, most of the representations proposed so far do not explicitly include LA based features. Small steps in this direction have been made in some areas, such as enactment support for tutors and students (Lejeune \& Gueraud, 2012); enhancements to content domain representations for self-assessment purposes, that lend themselves very well to provide a map

\footnotetext{
${ }^{16}$ http://www.metis-project.org/index.php/it/
} 
of students achievements and have been used in this way for many decades (Ferraris, Midoro, Olimpo, Persico, \& Sissa, 1985); and self-regulation of students participation (Gewerc-Barujel, Montero-Mesa, \& Lama-Penín, 2014).

However, some work has been done to address the use of representations in the LA research field, but the way this should affect LD representations is far from being clear. 


\section{Approaches}

A number of approaches to LD have also been defined, and these are usually based on the general principles of the ADDIE umbrella model and adapt it to some specific learning context (face-to-face, online or blended) or to some kind of pedagogical approach (collaborative learning, self-regulated learning, or other pedagogical approaches). Some pedagogy oriented approaches have already been endowed with LA capabilities (e.g. Social Network Analysis for socio constructivist approaches). Other approaches, like those based on the idea of giving designers access to databases of pedagogical principles, could be enhanced by including in these databases data-sets processed with LA techniques.

\section{Tools}

Several tools aiming to support the LD process according to the above approaches have been developed. Some of these tools are related to one of the above mentioned approach; other tools use different kinds of representations to support reflection and pedagogical planning, yet others intend to facilitate the creation and circulation among practitioners of design ideas and best practices in the field. Recommendation systems based on LA techniques could be used also to support these practices. More recently, some of these tools have been complemented with social networking functionalities (e.g.: Cloudworks, ILDE, Learning Designer etc.) so to foster the creation of communities. The idea behind this is to establish a participatory culture of design among practitioners, and to favour the habit of seeing design as an inquiry process in which educators engage using these representations, methodologies and tools to sustain scientifically informed creative practices in their professional context.

\section{Moving towards teacher led inquiry}

More generally, all of the tools use a representation type and assume, implicitly or explicitly, one approach, so the three areas of work discussed above are strictly related and intertwined. In all cases, the availability of data about previous use of a learning design to inform the designer decision-making process would help the transformation of LD from a craft into evidence based inquiry. The sharing and reuse should not be limited to the designs or the learning resources, but also to the data collected during the implementation of a design, thus redefining the concept of good practice to meet accountability expectations of educational institutions and moving in the direction of a digital scholarship of designers and teachers.

Despite the efforts to support the work of designers and the strong emphasis posed on the need for a participatory culture of LD, the communities born so far around some of these tools or approaches are still facing difficulties in growing and sustaining themselves after the end of the projects that originated them. None of the tools, representations or approaches has yet achieved general consensus, neither within the scientific community, nor among practitioners. This is a major limitation of the results achieved so far in this research field, in spite of its fairly long history.

In particular, as far as representations and formalisms, it should be acknowledged that there is still a lot of work to do and that involving actively the communities of practitioners to fine tune existing representations and formalisms is of paramount importance. The importance of this area of work is perhaps underestimated by practitioners, who apparently do not perceive the need for a formalism that allows to describe in a complete and unambiguous way a learning design. However, this is an essential pre-condition to make the designs sharable and to automate their implementation. On the side of the researchers, instead, the need for representations that simplify the work of designers should be regarded as of paramount importance, if it is true that the failure of some of the major LD projects is due to a low degree of user-friendliness of the representations proposed (Burgos, 2010). 
As far as LD approaches, there is a clear tension between the attempt to define a general purpose approach, independent of specific pedagogical theories, and the tendency to define more specific approaches suitable to particular contexts. In addition, there is a need to develop and disseminate LD competence among teachers, which isn't always fulfilled by tools and approaches that seem to assume that high level decision-making has already taken place, and that the main problem is the choice of the most suitable tool for a given type of activity. LA, by providing access to data concerning previous and ongoing learning processes and contexts, can support the design decision-making process before a learning initiative, ongoing adaptation during it, and its evaluation, to inform further initiatives.

Lastly, in the area of tool development, an effort should be made to integrate and test ease of use, usability and effectiveness of already existing instruments, and to enhance them with LA tools, rather than devoting further energy to the creation of new LD tools. With this regard, the above mentioned METIS project seems to be on the right track, thus paving the way to improvements in this field.

\section{Conclusions}

While we agree that the work that has been done in the field of LD is impressive, we contend that there still is much work to be done if we want to succeed in developing the said participatory culture that is likely to favour a wider and better use of technology in education.

As it often happens, in order to understand the way ahead in a given line of work, the best thing to do is to recall why we are doing it and what exactly we are trying to achieve. Summarizing, LD addresses the decision-making process of individual teachers and designers who feel the need to make informed decisions about the tools to use and the most suitable learning strategies to adopt. These teachers usually rely on their own previous experience and their own implicit or explicit tenets about the way their subject and their students can best be taught. However, if these were the only parameters influencing their decisions, there would hardly be changes in the way a teacher works throughout their career. Luckily, teachers are also informed and influenced by best practice and innovations tried out by competent colleagues, by information and data about the students experience in many formal and informal learning contexts, and by state of the art knowledge about how learning takes place. The power of the participatory culture pursued by LD research lies in the fact that, if the teacher is a member of a community of practice, the influence of these external parameters is amplified and modifies the practices of the community members, because their assumptions are continually challenged and undergo a kind of inquiry based verification. In this view, taking advantage of results in the field of LA is likely to increase the robustness of the designs shared, make the decision-making process involved in LD better grounded in evidence and the exchanges between designers more anchored to actual teaching and learning practice. In other words, teachers would become educational researchers, pursuing innovation not only to take advantage of the affordances of technology, but also to deal with the continuously evolving needs of learners.

In this view, the answer provided by LD research cannot be that of producing a plethora of different representations, approaches and tools that are not interoperable. If the METIS project is on the right track with its promise to support the creation of a community of designers, there is still a risk that the members of such a community do not understand each other because they use different representation formalisms, tools, and approaches. So the way ahead can only be that of making the representation formalisms so easy to use that everybody can quickly learn them, and pursue interoperability of the available tools so that users can actually share their design even if they have been produced with different tools, or have been represented with different formalisms. Research policies in this area should therefore support integration efforts (among LD tools and other research areas like LA) to improve the quality of the designs and their replicability, thanks to data about their use and usability. 


\section{References}

Agostinho, S. (2009). Learning Design Representations to Document, Model, and Share Teaching Practice. In L. Lockyer, S. Bennett, S. Agostinho \& B. Harper (Eds) (2009) Handbook of Research on Learning Design and Learning Objects: Issues, Applications, and Technologies (pp. 1-19). Hershey, PA: Information Science Reference.

Agostinho, S. (2011). The use of a visual learning design representation to support the design process of teaching in higher education. Australasian Journal of Educational Technology, 27(6), 961-978.

Aviv, R., Erlich, Z., Ravid, G. \& Geva, A. (2003) Network analysis of knowledge construction in asynchronous learning networks, Journal of Asynchronous Learning Networks, 7(3), 1-23.

Bakharia, A. \& Dawson, S. (2011). SNAPP: A Bird's-Eye View of Temporal Participant Interactions. In Proceedings of the 1st International Conference on Learning Analytics \& Knowledge. (pp. 168-173). NY, USA: ACM NEW York

Blikstein, P. (2011). Using learning analytics to assess students' behavior in open-ended programming tasks. In: Proceedings of the 1st International Conference on Learning Analytics \& Knowledge (pp.110-116). NY, USA: ACM New York.

Britain, S. (2004). A Review of Learning Design: Concept, Specifications and Tools: A report for the JISC Elearning Pedagogy Programme. Retrieved July, 30 ${ }^{\text {th }}$ 2014, from http://www.jisc.ac.uk/media/documents/programmes/elearningpedagogy/learningdesigntoolsfinalreport.pdf

Burgos, D. (2010). What is wrong with the IMS Learning Design specification? Constraints And Recommendations. Proceedings of LWA2010 - Workshop-Woche: Lernen, Wissen $\backslash \&$ Adaptivitaet, Kassel, Germany. Retrieved July, 30 ${ }^{\text {th }}$, 2014, from http://www.kde.cs.uni-kassel.de/conf/lwa10/papers/abis8.pdf

Conole, (2010a). Learning design - Making practice explicit. In ConnectEd 2010: 2nd International conference on Design Education, 28 June - 1 July 2010, Sydney, Australia.

Conole, G. (2010b). An overview of design representations. In L. Dirckinck-Holmfeld, V. Hodgson, C. Jones, M. de Laat, D. McConnell, \& T. Ryberg (2010). Proceedings of the 7th International Conference of on Networked Learning 2010 (pp.482-489).

Conole, G. (2013). Designing for learning in an open world. New York: Springer.

Dalziel, J. R. (2003). Implementing Learning Design: The Learning Activity Management System (LAMS). In G. Crisp, D. Thiele, I. Scholten, S .Barker, \& J. Baron (Eds), Interact, Integrate, Impact: Proceedings of the 20th Annual Conference of the Australasian Society for Computers in Learning in Tertiary Education (pp.593-596). Adelaide, 7-10 December 2003. Retrieved July, 30 ${ }^{\text {th }}$ 2014, from http://www.melcoe.mq.edu.au/documents/ASCILITE2003\%20Dalzie1\%20Final.pdf

De Laat, M., Lally, V., Lipponen, L. and Simons, R.-J. (2007). Investigating patterns of interaction in networked learning and computer-supported collaborative learning: a role for social network analysis, International Journal of Computer Supported Collaborative Learning, 2, 87-103.

De Liddo, A., Buckingham Shum, Derntl, M., Neumann, S., \& Oberhuemer, P. (2011). Community Support for Authoring, Sharing, and Reusing Instructional Models: The Open Graphical Learning Modeller (OpenGLM)', Proceedings of 10th IEEE International Conference on Advanced Learning Technologies, ICALT 2011, Athens, Georgia, USA, (pp.431-435).

Dias, S. B., \& Diniz, J.A. (2013). FuzzyQoI Model: A fuzzy logic-based modelling of users' quality of interaction with a learning management system under blended learning. Computers \& Education, 69, 38-59. DOI: 10.1016/j.compedu.2013.06.016

Dobozy, E. (2011). Typologies of learning design and the introduction of a "LD-Type 2" case example'. eLearning Papers, 27(27), 1-11.

Earp, J., Ott, M., \& Pozzi, F. (2013). Facilitating Educators' Knowledge Transfer with Information Systems for Sharing Practices, Computers in Human Behaviour, 29, 445-455.

Emin, V., Pernin, J.-P. \& Aguirre, J.-L. (2010). ScenEdit: An Intention-Oriented Authoring Environment to Design Learning Scenarios. Proceedings of the European Conference on Technology-Enhanced Learning (EC-TEL 2010), Barcelona, Spain, 626-631.

Emin, V., Pernin, J.-P., \& Guéraud, V. (2009). Model and tool to clarify intentions and strategies in learning scenarios design, Proceedings of the European Conference on Technology-Enhanced Learning (EC-TEL 2009), Nice, France, 462-476.

Falconer, I., Beetham, H., Oliver, R., Lockyer, L. \& Littlejohn, A. (2007). Mod4L Final Report: Representing learning designs. July, $30^{\text {th }}, \quad$ from http://www.researchgate.net/publication/228379273_Mod4L_final_report_Representing_learning_designs/fil e/79e41510c2dba4e1e9.pdf).

Ferguson, R. (2012). Learning analytics: drivers, developments and challenges. International Journal of Technology Enhanced Learning, 4(5), 304-317. 
Ferraris, M., Midoro, V., Olimpo, G., Persico, D., \& Sissa, G. (1985). Diagnostic Evaluation in the Learning Process. In: K. Duncan, D. Harris (eds), Proc. 4th World Conference on Computers in Education (WCCE85), Norfolk, VA (USA), 29/7-2/8 1985 (pp. 251-258). Amsterdam: North-Holland.

Gewerc-Barujel, A., Montero-Mesa, L., \& Lama-Penín, M. (2014). Collaboration and Social Networking in Higher Education. Colaboración y redes sociales en la enseñanza universitaria. Comunicar, 21(42), 55-63.

Goodyear, P., \& Retalis, S. (2010). Technology-enhanced learning: design patterns and pattern languages. Rotterdam: Sense Publishers.

Gustafson, K. L., \& Branch, R. M. (2002). What is instructional design? In Reiser, R, A. and Dempsey, J.V. (eds) Trends and Issues in Instructional Design and Technology, (pp.17-25). Columbus: OH, Merrill Prentice Hall.

Hernández-Leo, D., Romeo, L., Carralero, M.A., Chacón, J., Carrió, M., Moreno, P. \& Blat, J. (2011). LdShake: Learning design solutions sharing and co-edition. Computers \& Education, 57(4), 2249-2260.

Hernández-Leo, D., Villasclaras-Fernández, E. D., Asensio-Pérez, I. M., Jorrín-Abellán, I., Dimitriadis, Y., RuizRequies, I. \& Rubia-Avi, B. (2006). Collage, a collaborative learning design editor based on patterns'. Educational Technology \& Society, 9(1), 58-71.

IMS Global Learning Consortium (2003). IMS Learning Design Best Practice and Implementation Guide. $\begin{array}{lllll}\text { Retrieved July, } & 30^{\text {th }}, & 2014, & \text { from }\end{array}$ http://www.imsglobal.org/learningdesign/ldv1p0/imsld_bestv1p0.html\#1534949

Kali, Y. (2008). The Design Principles Database as means for promoting design-based research. In A. E. Kelly, R. A. Lesh, \& J. Y. Baek (Eds.), Handbook of design research methods in education (pp. 423-438). New York: Routledge.

Katsamani, M. \& Retalis, S. (2011) Making Learning Design in Layers. The Cadmos approach, IADIS Multi Conference on Computer Science and Information Systems, Rome, Italy.

Koper, R., \& Manderveld, J. (2004). Educational modelling language: modelling reusable, interoperable, rich and personalised units of learning. British Journal of Educational Technology, 35 (5), 537-552.

Laurillard, D., Charlton, P., Craft, B., Dimakopoulos, D., Ljubojevic, D., Magoulas, G., Masterman, E., Pujadas, R., Whitley, E.A. \& Whittlestone, K. (2011). A constructionist learning environment for teachers to model learning designs. Journal of Computer Assisted Learning, 29(1), 15-30.

Laurillard, D. (2008). The teacher as action researcher. Studies in Higher education, 33(2), 139-154.

Laurillard, D. (2012). Teaching as a Design Science: Building Pedagogical Patterns for Learning and Technology. New York: Routledge.

Lejeune, A., \& Gueraud, V. (2012). Embedding observation means into the learning scenarios: authoring approach and environment for simulation-based learning. In: Proceedings of the 12th IEEE International conference on Advanced Learning Technologies (ICALT).

Lockyer, L., Bennett, S., Agostinho, S., \& Harper, B. (Eds.) (2009). Handbook of research on learning design and learning objects: Issues, applications and technologies. Hershey, PA: Information Science Publishing.

Lockyer, L., \& Dawson, S. (2011). Learning Designs and Learning Analytics. Proceedings of the 1st International Conference on Learning Analytics and Knowledge (LAK '11), 153-156.

Lockyer, L., Heathcote, E., \& Dawson, S. (2013). Informing Pedagogical Action: Aligning Learning Analytics With Learning Design. American Behavioral Scientist.

McAndrew, P., Goodyear, P., \& Dalziel, J. (2006). Patterns, designs and activities: unifying descriptions of learning structures. International Journal Learning Technology, 2(2/3), 216-242.

Molenda, M. (2003). In search of the elusive ADDIE Model, Performance Improvement, Retrieved July, $30^{\text {th }}$, 2014, from http://www.comp.dit.ie/dgordon/Courses/ILT/ILT0004/InSearchofElusiveADDIE.pdf

Mor, Y. (2011). Design Narratives: An Intuitive Scientific Form for Capturing Design Knowledge In Education. In: Learning in the Technological Era 6th Chais Conference, (pp. 57-63). Israel: Open University.

Mor, Y., \& Craft, B. (2012). Learning design: reflections upon the current landscape. Research in Learning Technology - Supplement: ALT-C 2012 Conference Proceedings, 20, 85-94. Retrieved July, 30 ${ }^{\text {th }}$, 2014, from http://www.researchinlearningtechnology.net/index.php/rlt/article/view/19196

Mor, Y., \& Mogilevsky, O. (2013). The learning design studio: collaborative design inquiry as teachers' professional development. Research in Learning Technology, 21.

Olimpo, G. (1995). La struttura dei contenuti nello sviluppo del courseware. TD Tecnologie Didattiche, 3(1), 1521.

Olimpo, G., Bottino, R. M., Earp, J., Ott, M., Pozzi, F., \& Tavella, M. (2010). Pedagogical plans as communication oriented objects. Computers \& Education, 55(2), 476-488.

Paquette, G., Léonard, M., \& Lundgren-Cayrol, K. (2008). The MOT+ visual language for knowledge-based instructional design. In L. Botturi and S.T. Stubbs (Eds.), Handbook of Visual Languages for Instructional Design: Theories and Practices (pp. 133-154). Hershey, NewYork: Information Science Reference.

Pérez-Sanagustín, M., Santos, P., Hernández-Leo, D., \& Blat, J. (2012). 4SPPIces: A case study of factors in a scripted collaborative-learning blended course across spatial locations. International Journal of ComputerSupported Collaborative Learning, 7(3), 443-465. 
Persico, D. (1997). Methodological constants in courseware design. British Journal of Educational Technology, 28(2), 111-124.

Persico, D., Pozzi, F., Anastopoulou, S., Conole, G, Craft, B. Dimitriadis, Y., Hernández-Leo, D., Kali, Y, Mor, Y., Pérez-Sanagustín, M., \& Walmsley, H. (2013). Learning Design Rashomon I - Supporting the design of one lesson through different approaches. Research in Learning Technologies, 21 - Supplement "Art and science of learning design".

Persico, D., Pozzi, F., \& Sarti, L. (2009). Design Patterns for Monitoring and Evaluating CSCL Processes. Computers in Human Behavior, 25(5), 1020-1027.

Persico, D., \& Pozzi, F. (2013). The role of representations for the development of a participatory culture of Learning Design among educators, in D.Parmigiani, V. Pennazio, A. Traverso (eds), ATEE-SIREM Winter Conference Proceedings, Learning \& Teaching with Media \& Technology, 7-9/3/2013, Genoa, Italy, (pp.365372). Brussels, Belgium: ATEE AISBL.

Pozzi, F., \& Persico, D. (2013). Sustaining learning design and pedagogical planning in CSCL. Research in Learning Technologies, 21 - Supplement "Art and science of learning design".

Pozzi, F., Persico, D., \& Earp, J. (2014). A multi-dimensional space for learning design representations and tools, in B. Craft, Y. Mor \& M. Maina (eds) The art and science of Learning Design. Sense Publishers. Retrieved July, $30^{\text {th }}$, 2014, from http://cloudworks.ac.uk/cloud/view/6628

Prieto, L. P., Asensio-Pérez, J. I., Dimitriadis, Y., Gómez-Sánchez, E., \& Muñoz-Cristóbal, J. A. (2011) 'GLUE!PS: A multi-language architecture and data model to deploy TEL designs to multiple learning environments'. In Proceedings of the European Conference on Technology-Enhanced Learning (EC-TEL 2011) (pp. 285-298), Palermo, Italy.

Prieto, L. P., Dimitriadis, Y., Craft, B., Derntl, M., Émin, V., Katsamani, M., Laurillard, D., Masterman, E., Retalis, S. \& Villasclaras, E. (2013). Learning Design Rashomon II - exploring one lesson through multiple tools'. Research in Learning Technologies, 21 - Supplement "Art and science of learning design".

Reiser, R.A. (2001). A History of Instructional Design and Technology: Part II: A History of Instructional Design. Educational Technology Research and Development, 49(2), 57-67.

Rogers, E. (1995). Diffusion of Innovations. New York: Free Press.

Ronen, M., Kohen-Vacs, D., \& Raz-Fogel, N. (2006). Structuring, Sharing and Reusing Asynchronous Collaborative Pedagogy, Paper presented at the International Conference of the Learning Sciences, ICLS 2006, Indiana University, Bloomington IN.

San Diego, J.P., Laurillard, D., Boyle, T., Bradley, C. \& Ljubojevicb, D. (2008). Towards a user-oriented analytical approach to learning design. Research in Learning Technology, ALT-J, 16, 1, 15-29.

Smith, P. K., Mahdavi, J., Carvalho, M., Fisher, S., Russell, S., \& Tippett, N. (2008) Cyberbullying: its nature and impact in secondary school pupils, Journal of Child Psychology and Psychiatry, 49, 4, 376-385.

Smith, P. L. \& Ragan, T. J. (2005) Instructional Design, Wiley, Hoboken, NJ, USA.

The Larnaca Declaration on Learning Design (2012). Retrieved July, 30 ${ }^{\text {th }, 2014, ~ f r o m ~}$ http://www.larnacadeclaration.org/

Van Rooij, S. W. (2010). Project management in instructional design: ADDIE is not enough. British Journal of Educational Technology, 41(5), 852-864.

Villasclaras-Fernández, E. D., Asensio-Pérez, J. I., Hernández-Leo, D., Dimitriadis, Y., de la Fuente-Valentín, L., \& Martínez-Monés, A. (2011) Implementing Computer-Interpretable CSCL Scripts with Embedded Assessment: A Pattern Based Design Approach. In F. Pozzi \& D. Persico (eds.) Techniques for Fostering Collaboration in Online Learning Communities: Theoretical and Practical Perspectives (pp. 261-277). Hershey: IGI Global Publishing,

Walmsley, H. (2011). Best Practice Models for e-Learning. Retrieved July, 30 ${ }^{\text {th }}$, 2014, from http://bestpracticemodels.wiki.staffs.ac.uk/

Walmsley, H. (2012). Case study: a community of practice for constructivist professional development in elearning. Innovative Practice in Higher Education, 1(2). 


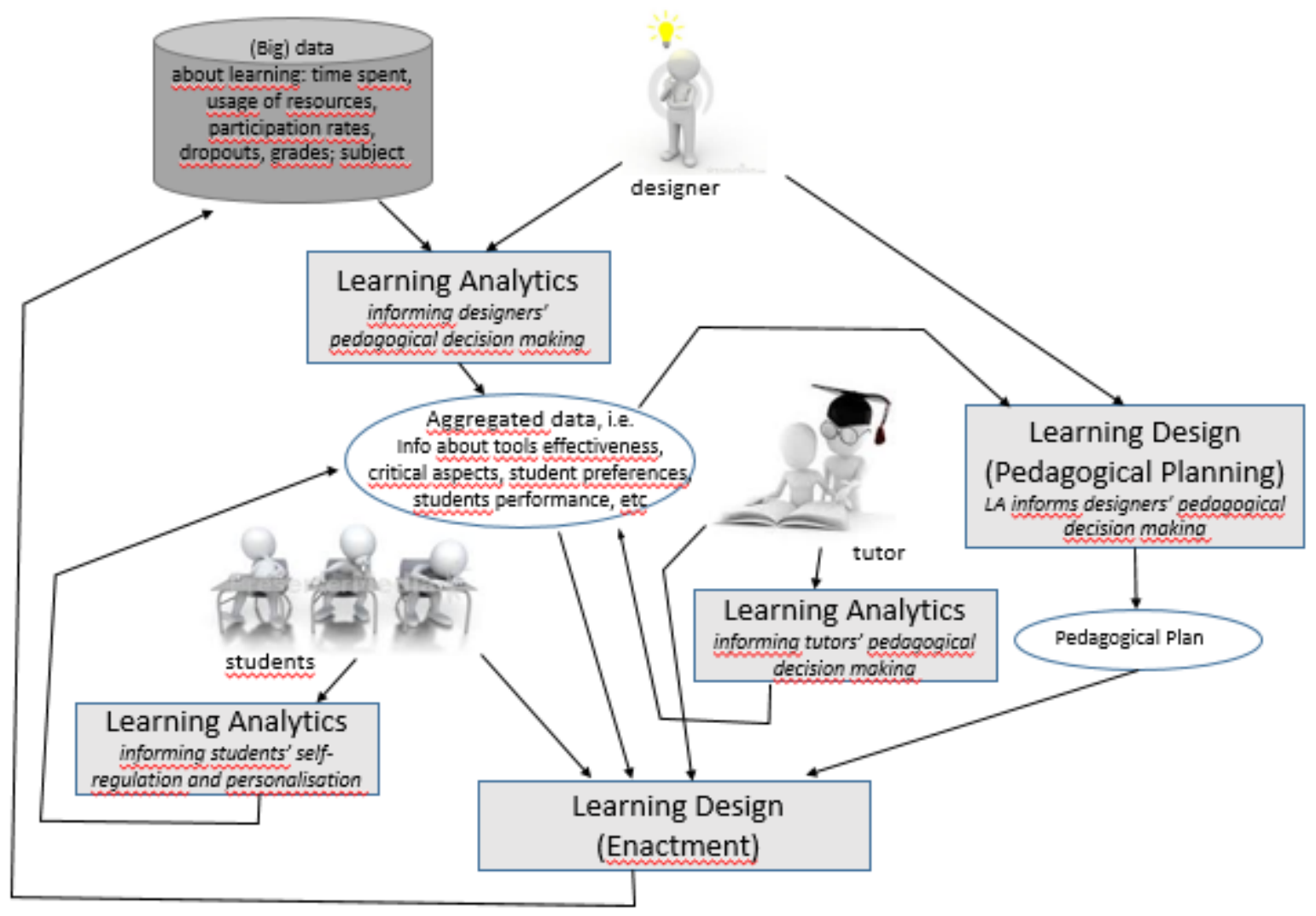

Figure 1: How LA can improve the learning process by informing decision-making of different actors involved. 
-The coordinator for the course makes a problem description available to the group (by uploading $a$ file to $a$ website).

- Each of the students in the group reads the

problem (on the website), as does the facilitator.

- (In a synchronous conferencing system which

includes the facilitator) The students decide who

is going to be the chairperson - the spokesperson

for the group, responsible for recording key group

decisions, and the chosen representative is

appointed as such by the facilitator.

- The group then communicate amongst

themselves to clarify the problem, using each

other and the facilitator to discuss and clarify

terminology and any open issues, eventually

arriving at their own succinct statement of the

problem at hand.

- The chairperson states this problem description

in a file uploaded to the website and the group

continues by identifying possible solutions or

explanations for the problem.

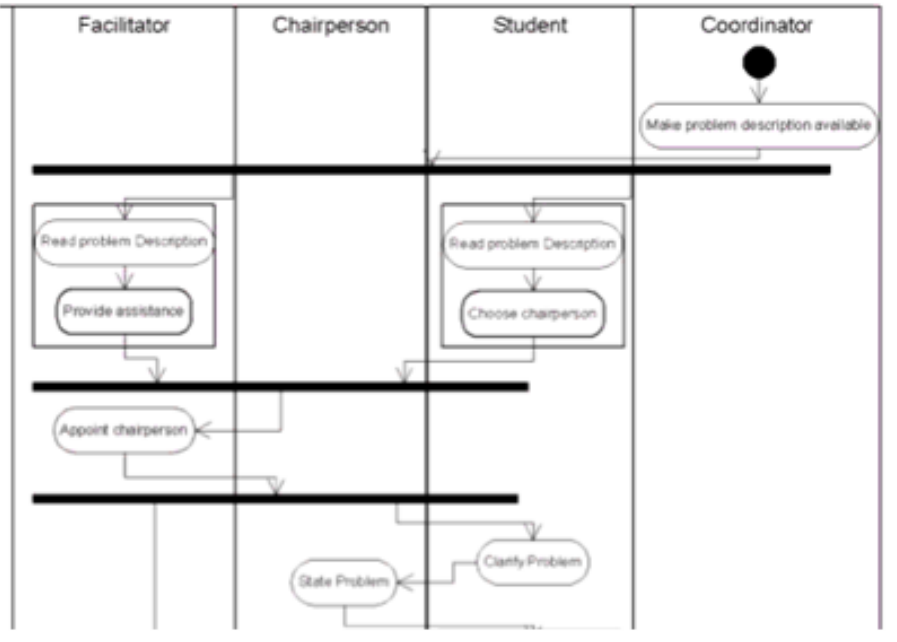

b

Figure 2: (a) Narrative representation of a Problem Based learning approach (b) its UML diagram (b). Excerpt from IMS Global Learning Consortium (2003). 